\title{
A New Way to Help Students Improve 3-D Visualization
}

\section{Dr. Dan G. Dimitriu, San Antonio College}

Dan G. Dimitriu has been practicing engineering since 1970 and taught engineering courses concurrently for more than 20 years at various institutions. In 2001, he joined San Antonio College full-time as the Coordinator of its Engineering program and in 2004 he joined also the faculty at University of Texas at San Antonio as an adjunct professor. He has been involved with several engineering societies and became a member of the Two-year College Division of ASEE in 2002. His research interests are in alternative fuels, fuel cells, plastics, and engineering education. 


\title{
A New Way to Help Students Improve 3-D Visualization
}

\begin{abstract}
There is ample evidence that instruction in spatial visualization skills is effective in improving outcomes for engineering students. Research conducted since the early 1990's has proven that spatial visualization practice and training leads to better grades in engineering graphics and in most other engineering coursework. Other studies demonstrate that improved 3D visualization skills improve retention and graduation rates in general and, in particular, the retention and graduation rates of underrepresented groups in the field of engineering.

The exercises described below offer a new method of challenging students to create three dimensions from two. These exercises are a powerful and effective way to help engineering and architecture educators teach spatial visualization.

Most of the 3-D visualization exercises currently being used by students in Design and Graphics classes present the objects in isometric views already in 3-D, asking the viewer to create multiple views, fold patterns, manipulate, reflect, or rotate them. Exercises present the objects in incomplete multi-view projections, and ask the students to add missing lines. They use mostly real 3D objects that are easily recognizable to help the student correlate 2D with 3D.

This new method uses a different approach. Each view of the solid represents a letter of the alphabet. The standard multi-view projections of the object present only the letter contours. The viewer must visualize the object in 3D and complete the views by adding all the missing visible, hidden, or center lines. The letters are by definition flat, with 2D images, and when they are combined to create the standard views of a 3D object, visualizing the object becomes quite a challenge.
\end{abstract}

This new method was used for over eight years with demonstrated success for students with a wide variety of visualization skills. It is intended as a tool to help Engineering, Architecture, and Art students and faculty who want to increase their 3-D visualization skills.

\section{Introduction}

The ability to visualize in a 3D environment is an essential skill for communication through graphics. It has been defined as "the ability to mentally imagine, understand, rotate, and 
manipulate geometric objects" ${ }^{(1-3)}$. Spatial skills are very important for a large variety of

careers. In 1964 Smith $^{4)}$ identified at least 84 career areas for which spatial skills are important. Studies have also shown that spatial visualization skills are a strong predictor of the success and confidence of engineering students ${ }^{(5-9)}$. A 2010 report on the role of women in STEM fields identifies spatial visualization skills as important for the success of women students in STEMrelated fields ${ }^{(10)}$. The report also presents findings that women and underrepresented minorities in STEM have comparatively lower spatial visualization skills, but that with specialized training those skills can be improved.

\section{D Visualization Training}

Continuous efforts have been made to create training methods and exercises that increase spatial visualization skills. In 2003 Sorby, Wysocki and Baartmans published a multimedia softwareworkbook package which contained the course "Introduction to 3D Spatial Visualization" (11), now used for engineering graphics education throughout the nation. In 2009 Sorby identified the connections between developing 3-D spatial skills and their contribution to student success ${ }^{(12)}$. In 2013 Uttal, et al. ${ }^{(13)}$, published a meta-analysis of more than 200 studies on improvement of spatial skills and found that the average effect size of improvement for students who receive extensive training and practice on spatially-relevant skills, such as mentally rotating 3D shapes, was .53 (equivalent to an intervention improving SAT scores by more than 50 points or IQ scores by more than 7.5 points). They also found that the improvements provided by training last over time, after training is completed.

\section{Testing of Visualization Skills}

As the need for 3D visualization skills increased, specific spatial tests had to be developed to measure these visualization skills. Eliot and Smith $(1983)^{(14)}$ and Mohler $(2008)^{15)}$ reviewed and categorized numerous spatial ability research and tests in order to determine the most effective ways to help students improve their 3-D visualization skills. Analysis of test(s) which can be used to measure specific factors that support spatial ability development in students ${ }^{(16,17)}$ have led researchers to identify as the top three tests the Mental Cutting Test (MCT), Mental Rotations Test (MRT), and Purdue Spatial Visualization Test: Visualization of Rotations (PSVT: VR) ${ }^{(18)}$. 


\section{A New 3-D Visualization Challenge}

Most of the 3-D visualization exercises currently being used present objects in isometric views already in 3-D, asking the viewer to create multiple views, fold patterns, manipulate, reflect, or rotate them. Generally they require a conversion from a given 3D image to one or more 2D images, but very few challenge the student to create three dimensions from two. The folding of a flat pattern into a 3-D shape might be considered the closest to this kind of challenge, but even this exercise has connections for some of the students with various kinds of packaging, wrapping, or with origami.

A new type of training exercise has been developed to increase the level of abstract thinking to create 3-D objects from universally accepted 2-D flat patterns. Since we read and write on 2-D surfaces, the shapes we associate most with a 2-D environment are alphabetic letters. Combining letters in a 3-D environment creates extremely challenging exercises for visualizing 3-D shapes. Extensive research has been conducted to understand the way in which letters are perceived and coded in the human brain. ${ }^{(19-21)}$ Students are familiar with writing and print so they are trained to recognize characters of a familiar writing system in 2-D. Although brain activities have been identified for words and letter strings, relatively little work has focused on the neural basis of single-letter perception and none has focused on letter perception in a 3-D setting. Even the famous letter cubes present 2-D letters on each face of the cube which is a 2-D surface. Lane, et al. ${ }^{(22)}$ presents an interesting experiment involving the letter $\mathrm{T}$ in 3-D but it starts with an isometric sketch from a solid built by students and stops short of recognizing the contour of the letter I in the other standard views. 3D visualization of letters may open the door to research on how the brain adjusts from 2-D pattern recognition to a 3-D embodiment.

My new exercises use alphabet letters represented in standard multiview projections (front, top, right, left, or bottom side views). The 3-D object made up of the three letters, one in each view, has to be mentally assembled in 3-D, with no assistance from an isometric representation of the solution figure. The problems ask the solver to break out of the 2-D image of the letter and visualize the third dimension, the depth, or " $\mathrm{Z}$ axis", to create the other two letters from the other views of the 3-D object. The exercises are presented with increasing degrees of difficulty to help students improve their 3-D visualization skills. 
The collection of over 100 three-letter combinations training exercises has been published in a workbook format ${ }^{(23)}$ available in print and on line. Many of the exercises are presented with multiple solutions and a brief instructional text on how to solve these exercises. The problems build on the students' body of knowledge already developed in early stages of graphics core concepts introduction such as:

- Alphabet of lines (visible, hidden, and center lines)

- Multiview Orthographic Projections

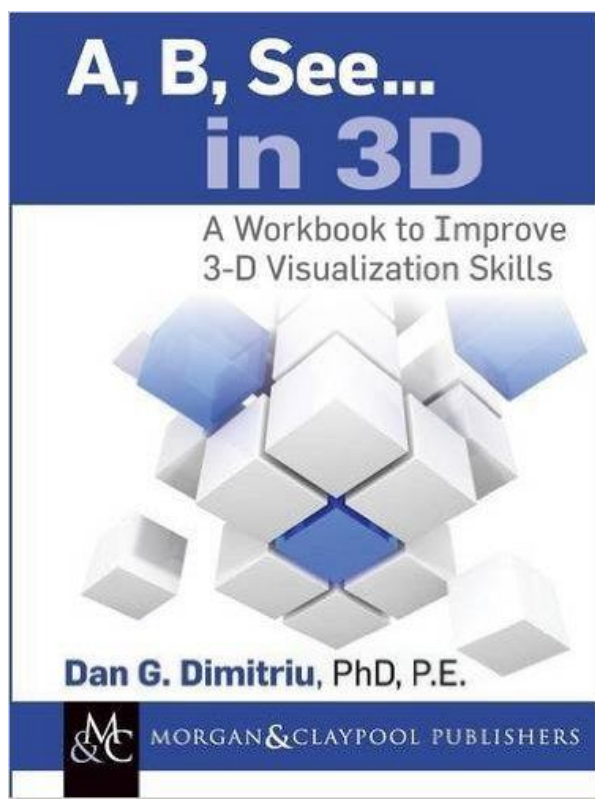

- Surface and Edge Classifications (Normal, Inclined, Oblique, and Curved)

The graphical problems are presented in order of increasing difficulty and designed to gradually break students out of their 2-D preconceptions about 3-D space. By completing the assignments the students learn how to visualize a variety of surfaces - normal, inclined, oblique and cylindrical - in multiple positions, visible and hidden, in edge view, true size and shape, or foreshortened.

Because letters are universally known, they are images that can be kept in mind by the student as they are mentally manipulated, rather than forcing the student to compare shapes on a page. They can work on the assignments everywhere, at home, at lunch, or when they go for a walk in the park. For this reason, the solutions for these exercises are also easy to compare with other students' solutions and argue about. In addition, within the alphabet soup is a progression of easy-to-difficult that gives students a sense of accomplishment as they advance through spatial skills levels. All letters of the alphabet are present in this workbook and while just as challenging as isometric workbook exercises, the letter-based problems appear more like puzzles, and therefore more like fun.

The exercises are organized following the letter combinations and by the level of difficulty. The first problems (Figures 1 and 2) show straight letters that can be made completely out of cubes and, with one exception, have only normal edges and surfaces. The challenge is to determine the exact number of cubes needed to make the object despite the fact that a cube might appear in 
more than one view. Figure 3 presents the Figure 2 that with the cubes erased shows just the contours of the letter $\mathrm{L}$ in three standard views and asks the student to add the missing lines in each view. Figure 4 and 5 present more advanced challenges.

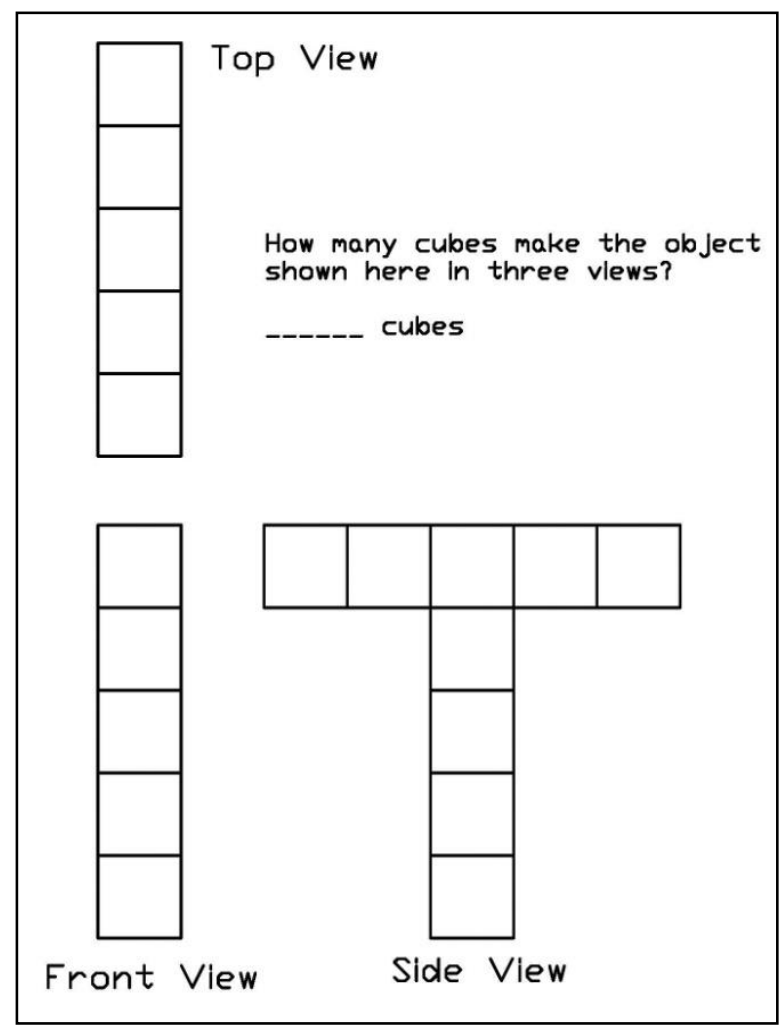

Figure 1

Solution: 9 cubes

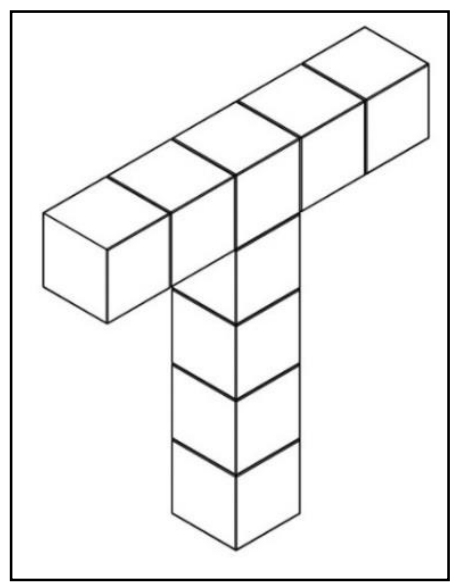

Figure 2
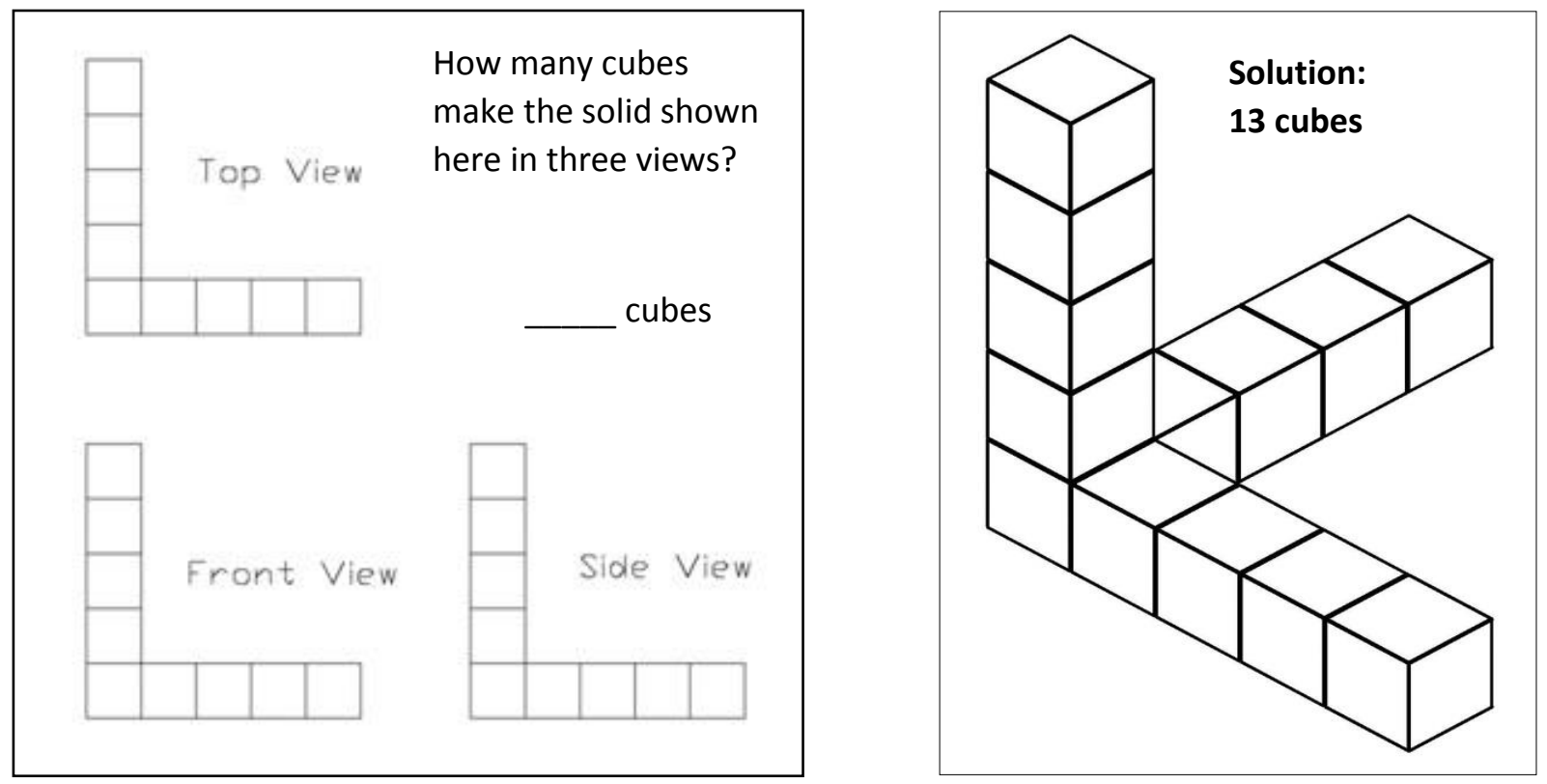
Figure 3

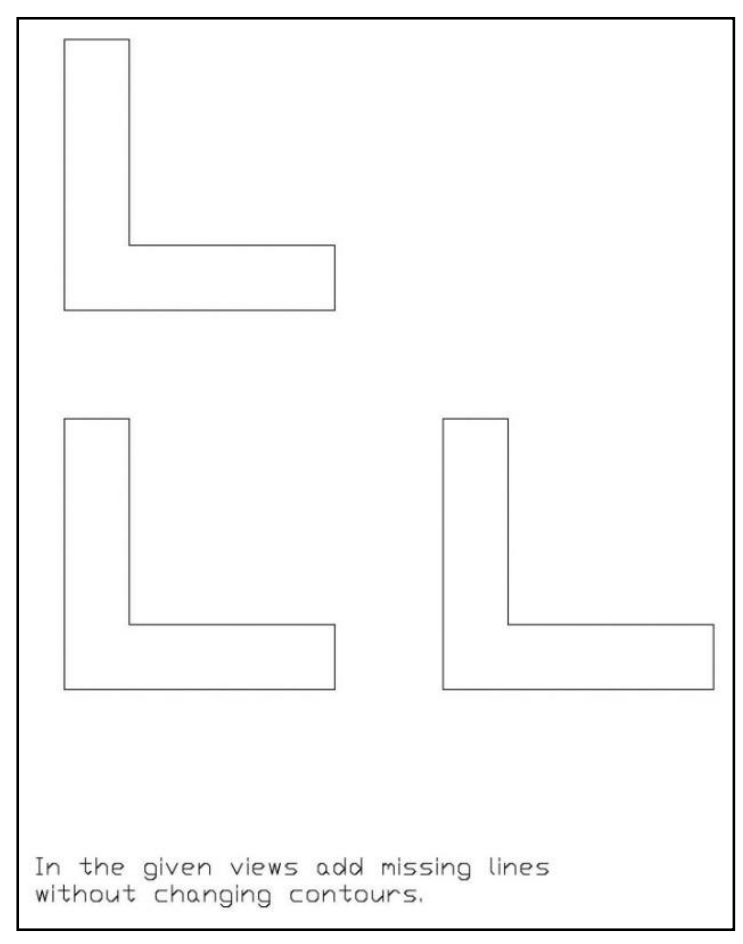

Figure 4
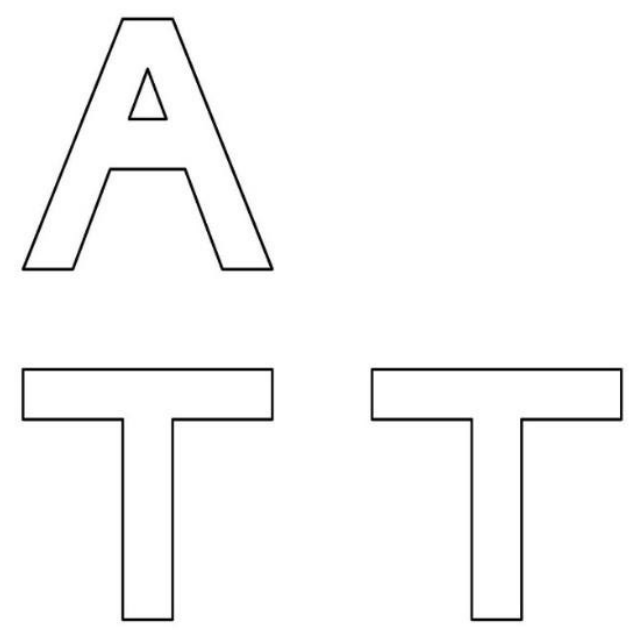

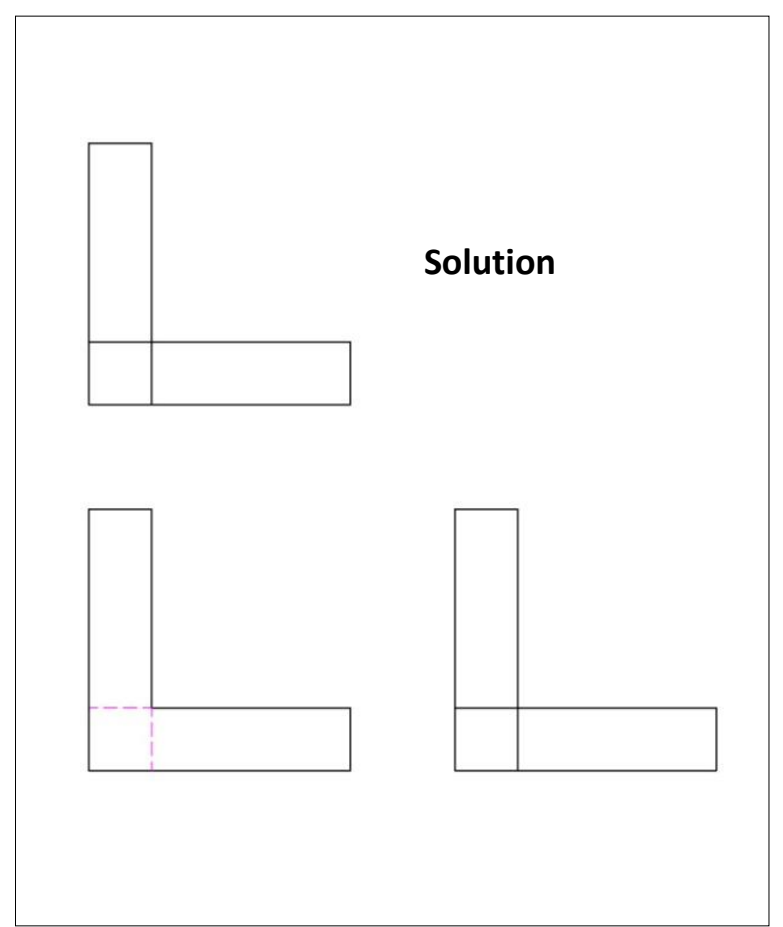

Figure 5
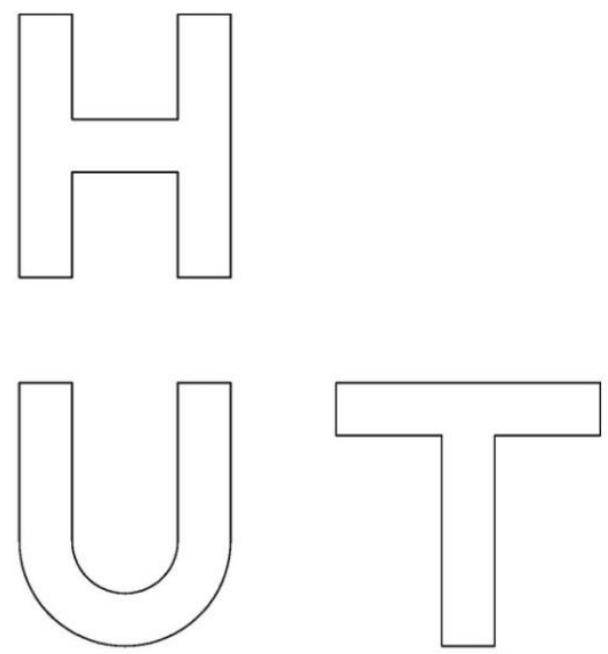
The second chapter of the workbook "First Level" takes the cube problems and by eliminating the cubes presents them as solids with straight faces without the cube partitions. Ten more combinations of letters define new solids in this chapter. The problems now ask the solver to place the missing lines standing for visible and hidden edges and surfaces within the confines of the contours to complete the views. It is suggested that each exercise should be limited initially to the following cross sectional shapes:
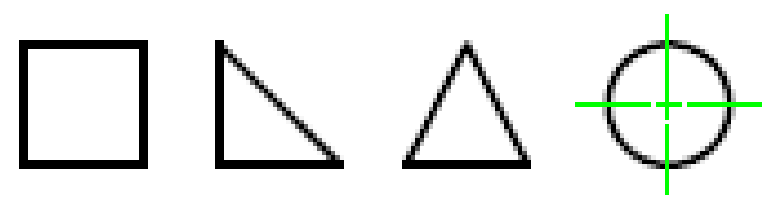

The following "Second Level" and "Third Level” chapters are increasingly challenging, as problem-solvers have to visualize letter parts that are not where they appear to be from the 2-D image. Almost all the problems have multiple solutions as the letter parts can be visualized as rectangular prisms, triangular prisms, or even cylindrical shapes, as indicated above. At this advanced stage students can experiment with other shapes as well such as a hexagon or a rhombus. The challenge is to have the correct representation with visible, hidden, and centerlines in each view. The advantage of all these exercises is that the solution can be easily verified for correctness by building a 3-D model with any 3-D modeling package. The standard front, top, and side view projections of the model should reveal all the necessary lines for verification.

Many times the students propose new solutions or start to look for new combination of letters, a challenge in itself because not all combinations of three letters can form a solid. This becomes another way to improve visualization abilities. Imagination is the only limit!

\section{Training Validation}

For the last five years the new visualization training method was included in two sections of an Engineering Graphics course. The course is a 3-Credit (2 lecture hours, 4 lab contact hours) course that introduces students to the basic rules of Engineering Graphics and their application in AutoCAD and 3-D Parametric Modeling Program Inventor. Enrollment was capped at 32 students per semester due to lab capacity and every semester we had full enrollment, so over 300 students participated in this type of training. The average enrollment of women in these classes was 15 to $18 \%$. 
For the first four weeks, during the hand-drawing period of the course, the students solved a variety of assignments. Among them were eight to ten letter-combination challenges with increasing difficulty levels. Each solution was discussed with multiple cross-sections and the students were encouraged to propose new letter combinations.

During this period the Purdue Spatial Visualization Test: Visualization of Rotations (PSVT: VR) was administered during the first and last day of class. The results are presented in Table 1.

\begin{tabular}{|l|c|c||c|c||c|c|}
\hline & $\begin{array}{c}\text { All } \\
\text { Students }\end{array}$ & Average & $\begin{array}{c}\# \\
\text { Males }\end{array}$ & Average & $\begin{array}{c}\# \\
\text { Females }\end{array}$ & Average \\
\hline Opening Results & 305 & 20.17 & $\mathbf{2 4 8}$ & 21.04 & $\mathbf{5 7}$ & 16.38 \\
\hline Closing Results & 218 & 24.34 & $\mathbf{1 9 2}$ & 24.61 & $\mathbf{2 6}$ & 22.35 \\
\hline
\end{tabular}

Table 1-Participating students in PSVT: VR

While the above results mirrored published results from other studies describing the PSVT:VR, the test could not evaluate the specific effect of the new 3-D visualization method versus effects from other elements of the course. Therefore a new, specific test had to be created.

\section{The Missing Letter Test (MLT)}

The development of the new 3-D visualization test was initiated in the fall semester of 2014. The test was inspired by the solutions presented in the workbook. The test was made only on timed PowerPoint slides and starts with the concept presentation and one example. It continues with timed challenges based on the complete solutions to totally new problems that were never discussed in class that had one of the standard views erased for the test. The students had a specific time interval to select what letter would fit as the missing view. The new test was named the "Missing Letter Test" or (MLT).

The spring 2015 semester was used to fine-tune the test by selecting the problems, the number of problems, what letters should be erased and the best font to be proposed as solution choices and the time interval between slides. Finally ten problems were selected and the students were asked to choose from five given letters which would fit as the missing view. The sixth choice was "none fits". The students had 45 seconds to make the selection. The font selection for the five proposed choices was the most difficult. Appendix 2 shows the four proposed fonts that were 
tested with the students. Four problems were submitted each with a different font and the students were asked to evaluate the font helpfulness in solving the problem.

The \#1, "Complete View" was abandoned because the students without any experience found it too confusing and the experienced students found it too easy and obvious. The \#4, "With Serif" was discarded for being too confusing and not representative as a missing view. The \#2, "Empty Contour" was by far the favorite followed by \#3, "Sanserif Bold". They were both preferred because they had the right contour without any other distracting details.

Starting with the fall Semester of 2015 the new test was fully introduced to assess the ability of students to visualize the 3-D configuration of objects having letter contours as standard views. The MLT test was administered right after PSVT: VR on the first and the last days of class. Of the 32 students who took the pre-test, 34\% scored below a 4 on the MLT (scoring range 0-10) and only one student got higher than a 7 . Table 2 presents the results for the 21 course completers who took both the pre- and post-test. Ultimately, the test will have 20 challenges on timed PowerPoint slides for a comprehensive evaluation of 3-D visualization skills.

\begin{tabular}{|c|c|c|c|c|c|c|c|}
\hline \multicolumn{8}{|c|}{ Missing Letter Test Pre- and Post-Test Scores } \\
\hline & \multirow{2}{*}{$\begin{array}{c}\text { Total } \\
\text { \# of } \\
\text { students }\end{array}$} & \multicolumn{3}{|c|}{ Males $(\mathrm{N}=18)$} & \multicolumn{3}{|c|}{ Females $(\mathbf{N}=3)$} \\
\hline & & $\begin{array}{c}\text { Scored } \\
0-3\end{array}$ & $\begin{array}{c}\text { Scored } \\
4-7\end{array}$ & $\begin{array}{c}\text { Scored } \\
8-10\end{array}$ & $\begin{array}{c}\text { Scored } \\
0-3\end{array}$ & $\begin{array}{c}\text { Scored } \\
4-7\end{array}$ & $\begin{array}{c}\text { Scored } \\
8-10\end{array}$ \\
\hline Pre-Test & 21 & 10 & 10 & 1 & 2 & 1 & 0 \\
\hline Post-Test & 21 & 1 & 13 & 4 & 0 & 2 & 1 \\
\hline
\end{tabular}

Table 2 - Participating students in MLT

Another test, the "Letter Projections Test" (LPT) is under development. Again this new test was made only on timed PowerPoint slides and starts with the concept presentation and one example. It continues with 20 timed challenges in which the viewers are presented with an isometric view of the object and are asked to list the letter contours projected as top, front, and right side views. (Appendix 3) 


\section{Conclusions}

For the last three years an anonymous survey was administered at the end of the hand drawing period to evaluate students' opinion regarding the new 3-D visualization training method. The results are presented in Table 3.

\begin{tabular}{|c|c|c|c|c|c|}
\hline Question/Choice & Extremely & Somewhat & $\begin{array}{c}\text { Not } \\
\text { very/Not } \\
\text { much }\end{array}$ & $\begin{array}{c}\text { Not } \\
\text { at } \\
\text { all }\end{array}$ & $\begin{array}{c}\text { Total } \\
\text { Responses }\end{array}$ \\
\hline $\begin{array}{c}\text { Do you consider 3D visualization } \\
\text { skills important for engineers? }\end{array}$ & $68 \%$ & $31 \%$ & $1 \%$ & 0 & 156 \\
\hline $\begin{array}{c}\text { Do you consider the "Alphabet Soup" } \\
\text { exercises challenging }\end{array}$ & $43 \%$ & $50 \%$ & $7 \%$ & 0 & 156 \\
\hline $\begin{array}{c}\text { Do you consider that the "Alphabet } \\
\text { Soup" exercises improved your 3D } \\
\text { visualization skills? }\end{array}$ & $33 \%$ & $46 \%$ & $13 \%$ & $8 \%$ & 156 \\
\hline $\begin{array}{c}\text { Would you recommend the "Alphabet } \\
\text { Soup" for training to improve 3D } \\
\text { visualization skills? }\end{array}$ & $36 \%$ & $39 \%$ & $14 \%$ & $11 \%$ & 155 \\
\hline
\end{tabular}

Table 3 - Survey results
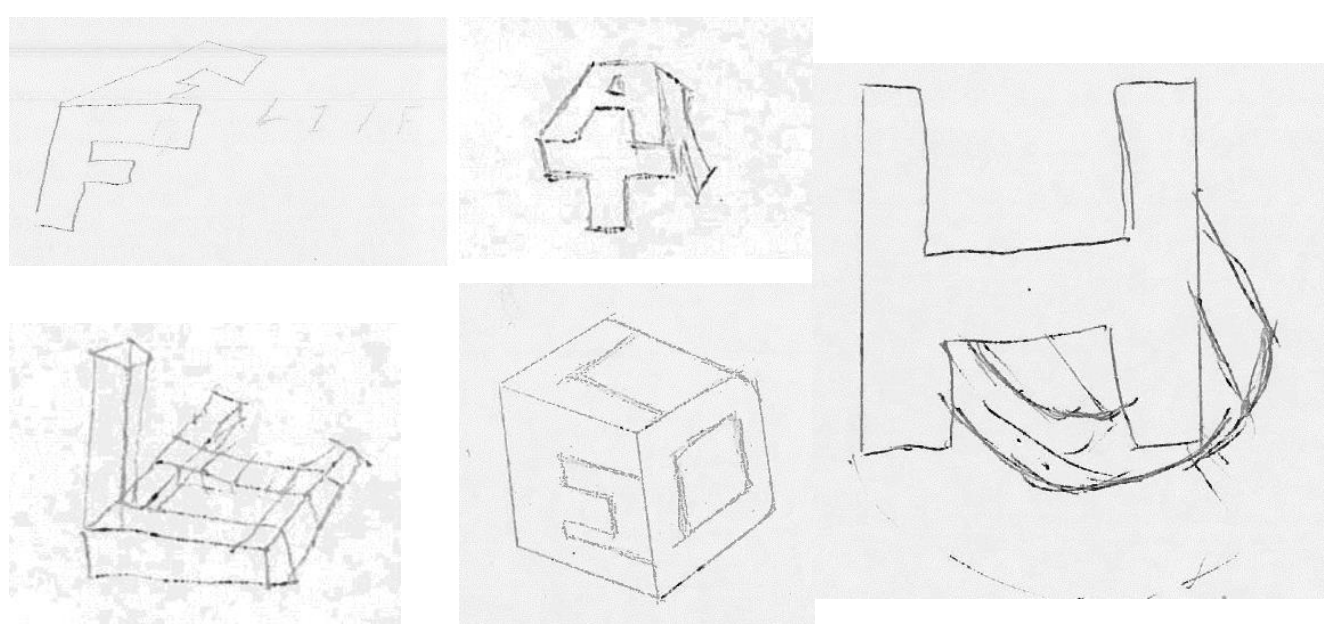

Figure 5

During the exercises and MLTs about 20 to $25 \%$ of the pre-test students attempt to create 3-D freehand sketches trying to represent the object. Figure 5 shows several of these sketches in which students have difficulty extracting the letters from their 2-D format and visualize them in 
the new 3-D environment. Very few of the post-test students needed to resort to freehand sketches and the ones that did were close to the 3-D image of the object.

Throughout the years the nickname of this set of exercises became "The Alphabet Soup" and the students' comments ranged from excitement and love to frustration and resignation. During two different semesters, two students, each diagnosed with dyslexia, had very similar comments. They both declared that, after these exercises, they looked at letters differently. When I asked for explanations they just said "I cannot explain it but I view letters differently now!"

With the acquisition of a 3-D printer in the spring semester of 2015 we could print several manipulatives (Figure 6), which greatly enhanced our students' ability to correlate the 2-D images with the 3-D solids. They were able visualize the abstract 2-D letters in the 3-D arrangement and observe the positions of visible and hidden features in each of the standard views. The effect of manipulatives on visualization skills will be the subject of future research. For now, we are hoping

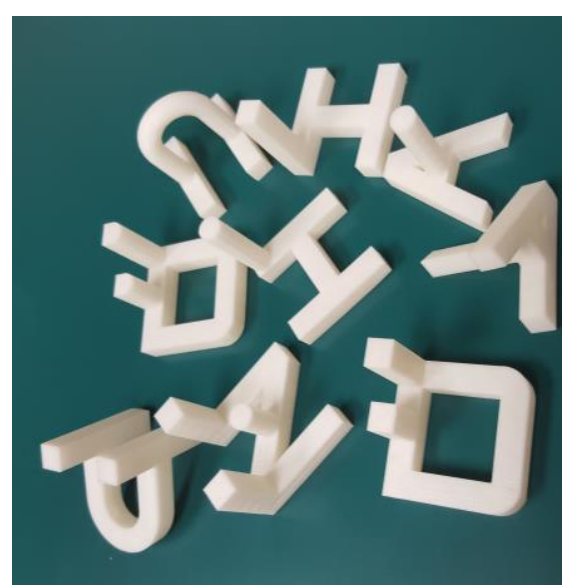

Figure 6 that increased use of the Alphabet Soup exercises and the MLT and LPT tests by engineering and architecture graphics faculty will allow us to gather more data to help us refine the method and increase the number of exercises.

The author wishes to extend his thanks to Susan Espinoza and Heather Cura for their invaluable help with editing and formatting the book and this paper and to all the students that participated in improving these exercises!

\section{References}

1. Ernst, J.V., Lane, D., and Clark, A.C., "Pictorial Visual Rotation Ability of Engineering Design Graphics Students", ASEE Annual Conference, Indianapolis, IN, 2014.

2. Kelly, F.W., Branoff, T.J., Clark, A.C.., "Spatial Ability Measurement in an Introductory Graphic Communications Course", ASEE Annual Conference, , Indianapolis, IN, 2014..

3. Katsioloudis, P., Jovanovic, V., Jones, M., "A Comparative Analysis of Spatial Visualization Ability and Drafting Models for Industrial and Technology Education Students, Journal of Technology Education, Vol. 26, No. 1, Fall 2014.

4. Smith, I. M., "Spatial ability-Its educational and social significance", University of London, London, 1964. 
5. Veurink, N.L., and Hamlin, A.J., Spatial Visualization Skills: Impact on Confidence and Success in an Engineering Curriculum", ASEE Annual Conference, , Vancouver, IN, 2011

6. Gimmestad, B. J., "Gender differences in spatial visualization and predictors of success in an engineering design course", Proceedings of the National Conference on Women in Mathematics and the Sciences, St. Cloud, MN, 133-136, 1989.

7. Blasko, D. G., Holliday-Darr, K, Mace, D., \& Blasko-Drabik, H. (2004). VIZ: The visualization assessment and training website Behavior Research Methods Instruments \& Computers. 36:2

8. Adanez, G.P., and Velasco, A.D., "Predicting academic success of engineering students in technical drawing from visualization test scores", Journal of Geometry and Graphics Vol. 6, No. 1, 2002, pp. 99- 109.

9. Veurink, N., and Sorby, S.A., "Raising the Bar? Longitudinal Study to Determine which Students Would Most Benefit from Spatial Training", ASEE Annual Conference, Vancouver, B.C., Canada, 2011.

10. Hill, C., Corbett, C., and St Rose, A., "Why So Few? Women in Science, Technology, Engineering, and Mathematics", ERIC, 2010.

11. Sorby, S., A., Wysocki, A. F., and Baartmans, B. J., "Introduction to 3D Spatial Visualization: An Active Approach (Book and CD), Published by Delmar Cengage Learning, 2003.

12. Sorby, S.A., "Educational research in developing 3-D spatial skills for engineering students", International Journal of Science Education, Vol. 31, No. 3, pp. 459-480, 2009.

13. Uttal, D.H., Meadow, N.G., Tipton, E., Hand, L.L., Alden, A.R., Newcombe, N.S., and Warren, C., "The Malleability of Spatial Skills: A Meta-Analysis of Training Studies", Psychological Bulletin 2013, Vol. 139, No. 2, 352-402

14. Eliot, J., \& Smith, I. M., “An international directory of spatial tests”, Highlands, NJ: NFER-NELSON, 1983.

15. Mohler, J.L., “A Review of Spatial Ability Research”, Engineering Design Graphics Journal, 72 (3), 2008.

16. Carroll, J. B. "Human cognitive abilities: A survey of factor-analytic studies”, Cambridge; New York: Cambridge University Press, 1993

17. McGee, M. G., "Human spatial abilities: Sources of sexual differences”, New York: Praeger Publishers, 1979.

18. Guay, R. W. "Purdue Spatial Visualization Test: Visualization of Rotations", Lafayette, IN, Purdue Research Foundation, 1977.

19. Wong, A. C.-N., Gauthier, I., Woroch, B., DeBuse, C., and Curran T., "An early electrophysiological response associated with expertise in letter perception", Cognitive, Affective, \& Behavioral Neuroscience 2005, 5 (3), 306-318

20. Grainger, J., Rey, A., and Dufau, S., "Letter perception: from pixels to pandemonium", Trends in Cognitive Sciences, Volume 12, Issue 10, October 2008, Pages 381-387

21. Rehling, McGraw, Goldstone and Hofstadter, "Dual Mechanisms Involved in Letter Perception", < http://www.cogsci.indiana.edu/farg/rehling/help/multiple-rep-draft/draft.html >

22. Lane, D., Hamlin, A.J., Veurink, N.L., and Seery, N., "The Role of Observational Sketching in Forming and Manipulating Graphical Libraries", ASEE Annual Conference, San Antonio, Texas, 2012

23. Dimitriu, D.G., "A, B, See... in 3D: A Workbook to Improve 3-D Visualization Skills", Morgan and Claypool Publishers, 2015

< http://www.morganclaypool.com/doi/abs/10.2200/S00669ED1V01Y201508ENG025?journalCode=eng > 


\section{Appendix I}

Solutions for Figures 4 and 5:
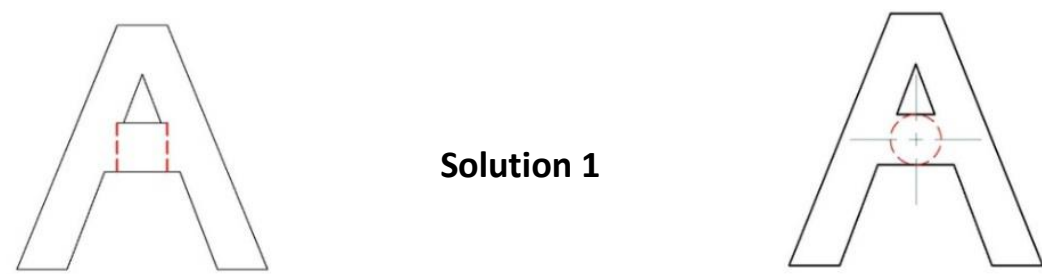

Solution 2

Solution 1
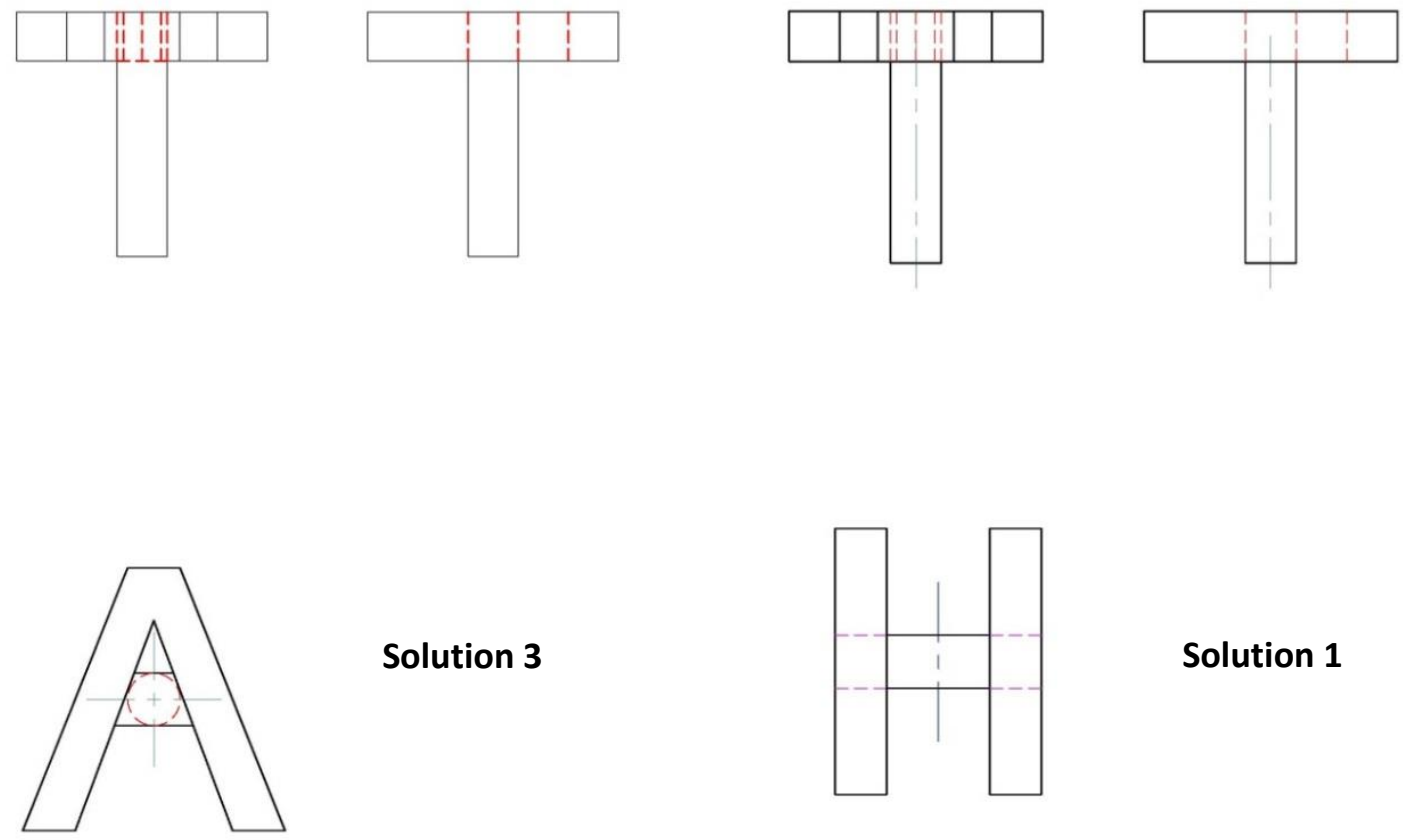

Solution 3

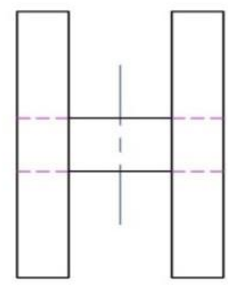

Solution 1
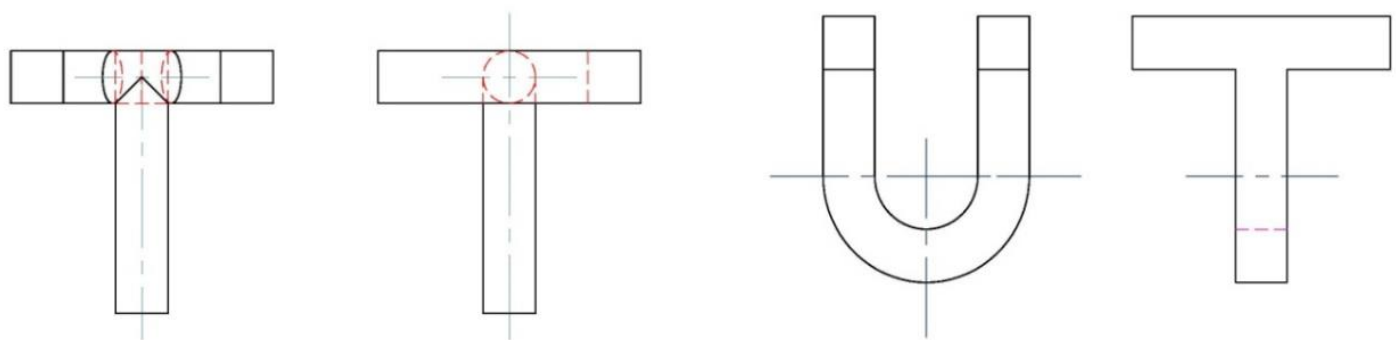


\section{Appendix II}

\section{Sample of the Missing Letter Test (MLT)}
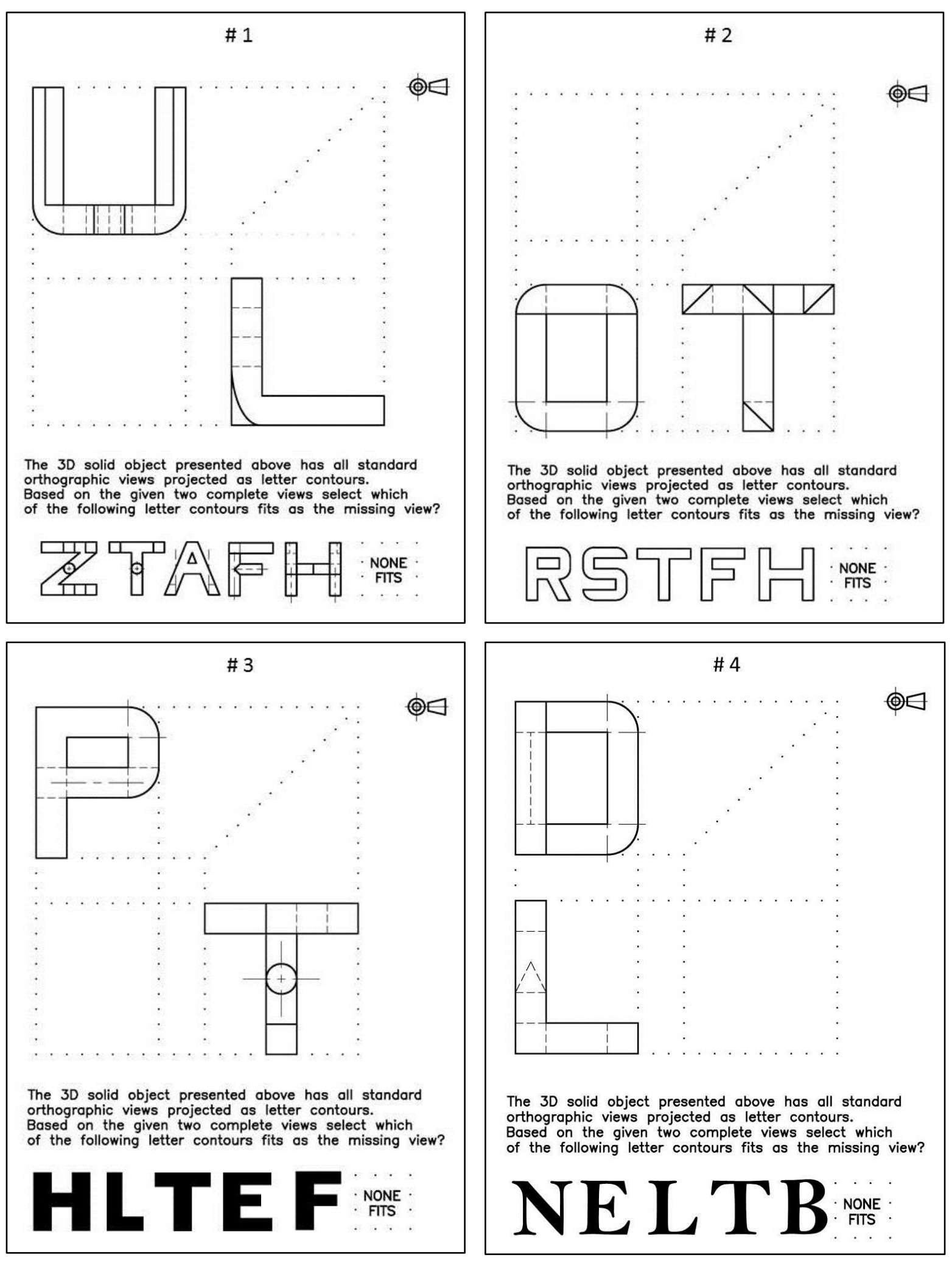


\section{Appendix III}

\section{Sample of the Letter Projections Test (LPT)}
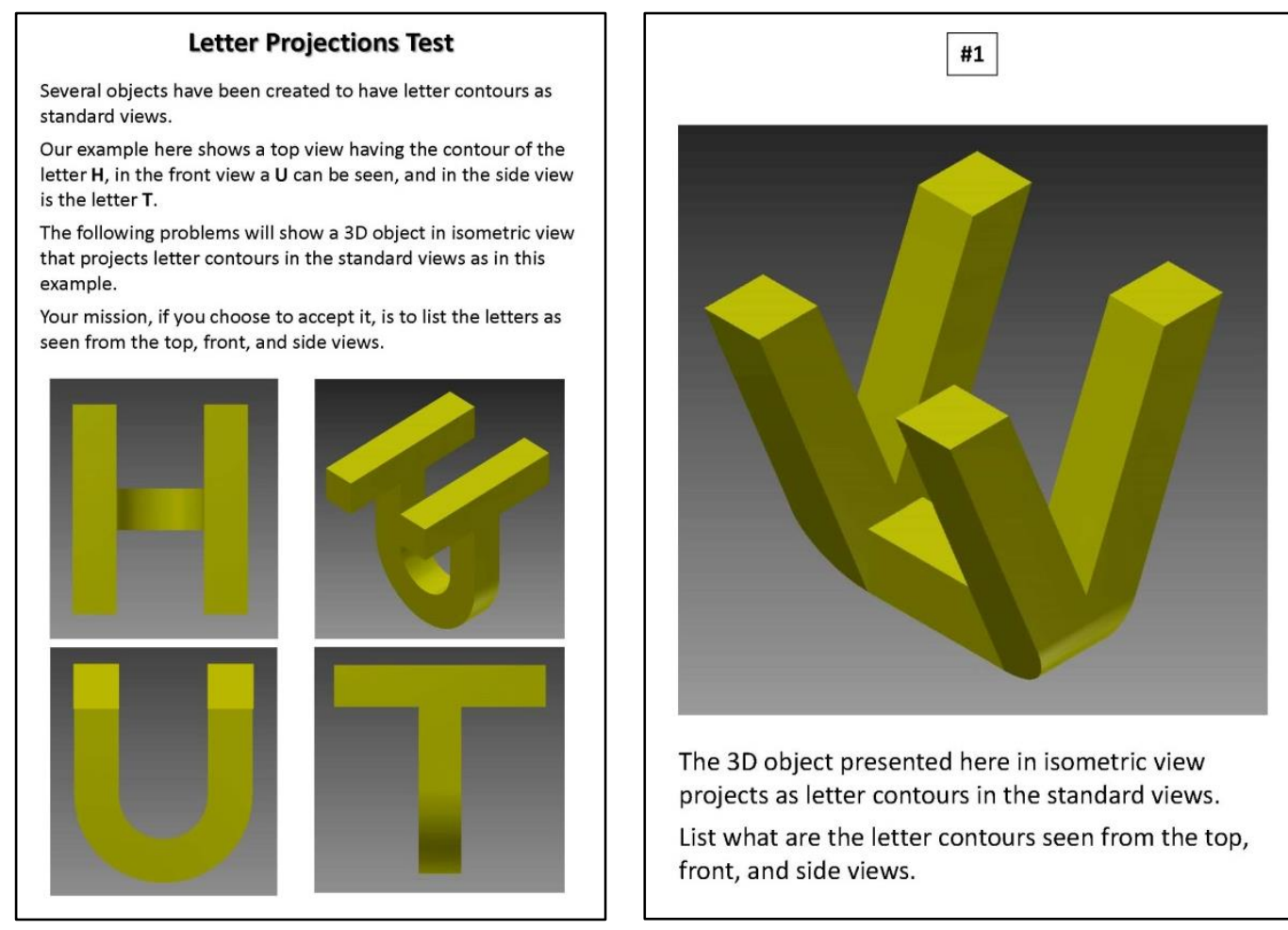

The 3D object presented here in isometric view projects as letter contours in the standard views.

List what are the letter contours seen from the top, front, and side views.

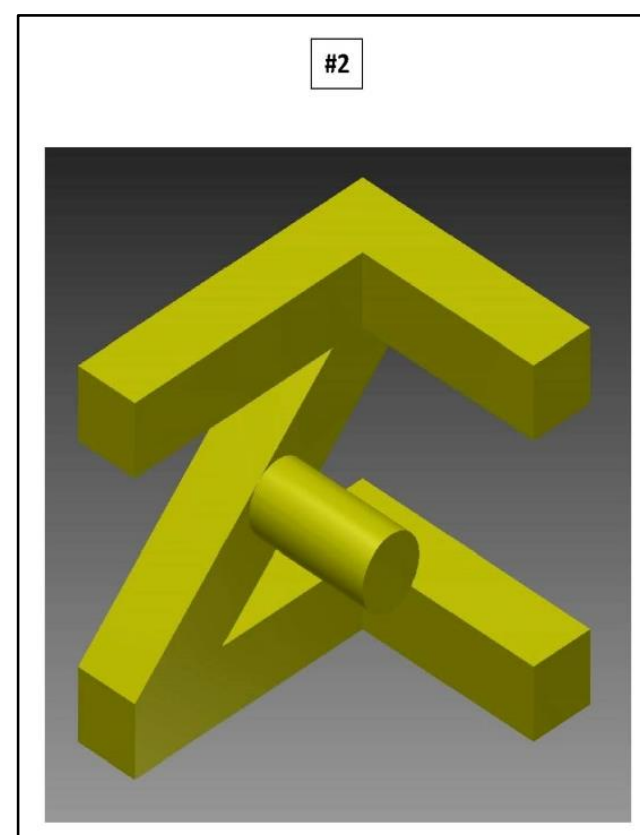

The 3D object presented here in isometric view projects as letter contours in the standard views.

List what are the letter contours seen from the top, front, and side views.

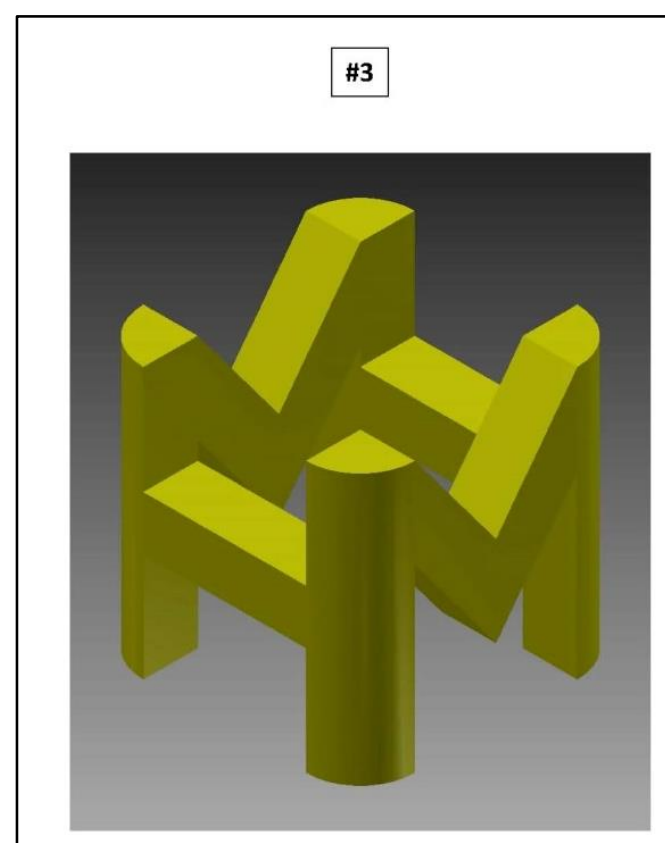

The 3D object presented here in isometric view projects as letter contours in the standard views. List what are the letter contours seen from the top, front, and side views. 